\title{
Electrogastrography: A noninvasive technique to evaluate gastric electrical activity
}

\author{
Claudia P Sanmiguel MD ${ }^{1}$, Martin P Mintchev PhD ${ }^{2}$, Kenneth L Bowes MD MSc FRCSC FACS ${ }^{2}$
}

CP Sanmiguel, MP Mintchev, KL Bowes. Electrogastrography: A noninvasive technique to evaluate gastric electrical activity. Can J Gastroenterol 1998;12(6):423-430. Electrogastrography (EGG) is the recording of gastric electrical activity (GEA) from the body surface. The cutaneous signal is low in amplitude and consequently must be amplified considerably. The resultant signal is heavily contaminated with noise, and visual analysis alone of an EGG signal is inadequate. Consequently, EGG recordings require special methodology for acquisition, processing and analysis. Essential components of this methodology involve an adequate system of digital filtering, amplification and analysis, along with minimization of the sources of external noise (random motions of the patient, electrode-skin interface impedance, electrode bending, obesity, etc) and a quantitative interpretation of the recordings. There is a close relationship between GEA and gastric motility. Although it has been demonstrated that EGG satisfactorily reflects internal GEA frequency, there is not acceptable correlation with gastric contractions or gastric emptying. Many attempts have been made to relate EGG 'abnormalities' with clinical syndromes and diseases; however, the diagnostic and clinical value of EGG is still very much in question.

Key Words: Electrogastrography, Gastric electrical activity, Gastric motility

\section{Électrogastrographie : technique non vulnérante pour évaluer l'activité électrique gastrique}

RÉSUMÉ : L'électrogastrographie (ÉGG) est l'enregistrement de l'activité électrique gastrique (AÉG) à partir de la surface du corps. Le signal cutané est de faible amplitude et, par conséquent, doit être considérablement amplifié. Le signal qui en résulte est très fortement contaminé par le bruit et l'analyse visuelle seule d'un signal d'ÉGG est, au mieux, imprécise. Par conséquent, les enregistrements d'ÉGG requièrent une méthodologie spéciale pour l'acquisition, le traitement et l'analyse des données. Les éléments essentiels de cette méthodologie reposent sur un système adéquat de filtration numérique, d'amplification et d'analyse, de même que sur la réduction des sources de bruits externes (mouvements aléatoires du patient, impédance de la surface électrode-peau, torsion de l'électrode, obésité, etc.) et une interprétation quantitative de l'enregistrement. On note un lien intime entre l'activité électrique gastrique et la motilité gastrique. Bien que l'on ait démontré que l'ÉGG témoigne de l'AÉG de façon satisfaisante, les corrélations avec les contractions gastriques ou la vidange gastrique ne sont pas suffisantes. De nombreuses tentatives ont été faites pour associer les anomalies de l'ÉGG à des syndromes cliniques et à des maladies. Toutefois, le diagnostic et l'utilité clinique de l'ÉGG demeurent douteux.

${ }^{1}$ Department of Surgery, University of Alberta, Edmonton; ${ }^{2}$ Department of Electrical Engineering, University of Calgary, Calgary, Alberta Correspondence: Dr Claudia Sanmiguel, Department of Surgery, University of Alberta, 2D4.06 MacKenzie Centre, Edmonton, Alberta

T6G 2B7. Telephone 403-492-6360, fax 403-4925069, e-mail cps1@gpu.srv.ualberta.ca

Received for publication November 12, 1997. Accepted May 28, 1998 
A lvarez (1) first recorded human electrical gastric activity from the body surface in 1921; however, until recently this technique - electrogastrography (EGG) - was largely ignored because of poor signal definition. Computer acquisition and analysis have dramatically improved signal quality and interest in EGG. A growing literature has emerged in the past decade about EGG, its accuracy and its clinical applications (2-4).

\section{GASTRIC MOTOR FUNCTION AND GASTRIC ELECTRICAL ACTIVITY}

Gastric motor function is a complex process whose purposes are to store ingested food, mix it with secretions and grind it into particles small enough to be emptied through the pylorus at a rate that permits efficient digestion and absorption. This complex process requires a fine modulation and coordination of motility in different parts of the stomach, pylorus and duodenum. Since the first studies of Cannon (5), the stomach has been divided into two different motor regions, each with different physiological functions (6-8). The proximal stomach (anatomical fundus and proximal one-third of the corpus) functions as a reservoir, controlling intragastric pressure and, consequently, the emptying of liquids. The distal stomach's major role is in the mixing, grinding and emptying of solid food.

The contractile pattern of each of these regions differs significantly. In the proximal stomach there are infrequent, long duration and low amplitude phasic contractions superimposed on a steady state contraction; in the distal stomach, peristaltic contractions predominate. During their distal propagation towards the pylorus, antral contractions increase in amplitude and velocity $(6,9)$. There is increasing evidence that both areas of the stomach play an important role in the emptying of both liquids and solids (10-13). At least a part of liquid emptying is pulsatile, indicating a probable role of the antrum (13). Similarly, decreased fundic tone has been related to delayed gastric emptying of both liquids and solids in patients with postsurgical gastroparesis syndrome (12).

Similar to their action in the heart, contractions of the stomach are preceded by electrical events. Very little work has been done on the electrical generation of contractions in the proximal stomach. Electrical events in the antrum, termed gastric electrical activity (GEA), on the other hand, have been extensively studied in animals and humans (6,9,14-17). These electrical events are the major factor determining frequency, velocity and direction of propagation of antral contractions. GEA is directly associated with phasic depolarization of gastric smooth muscle cells $(6,9,14-18)$. Isolated antral muscle cells undergo cyclic depolarizations known as electrical control activity (ECA) or 'slow waves'.

ECA frequency is not uniform throughout the distal stomach. Cells from the distal stomach depolarize at a much slower frequency (1 cycle/min) than cells from the more proximal stomach. In the intact antrum, however, the frequency of the slower cells is increased to that of an adjacent higher frequency cell. The higher frequency cells are located

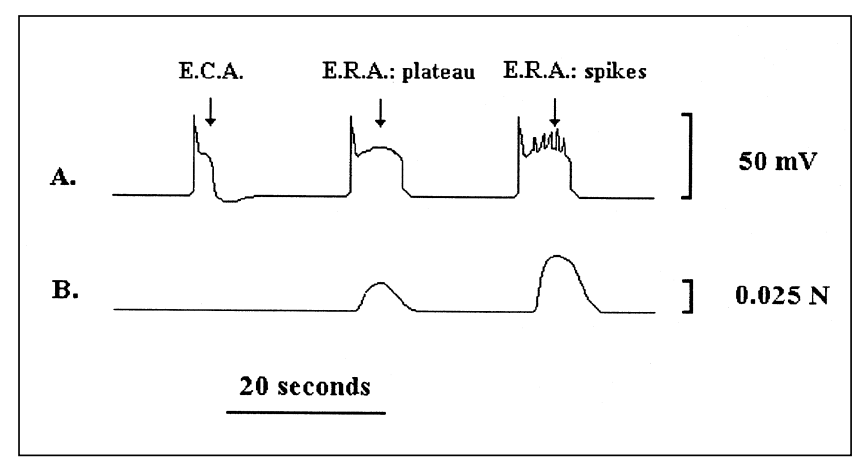

Figure 1) Intracellular electrical activity (A) and the corresponding contractile force (B). Electrical response activity (ERA) and particularly its second component, spikes, are associated with gastric contractions. ECA Electrical control activity

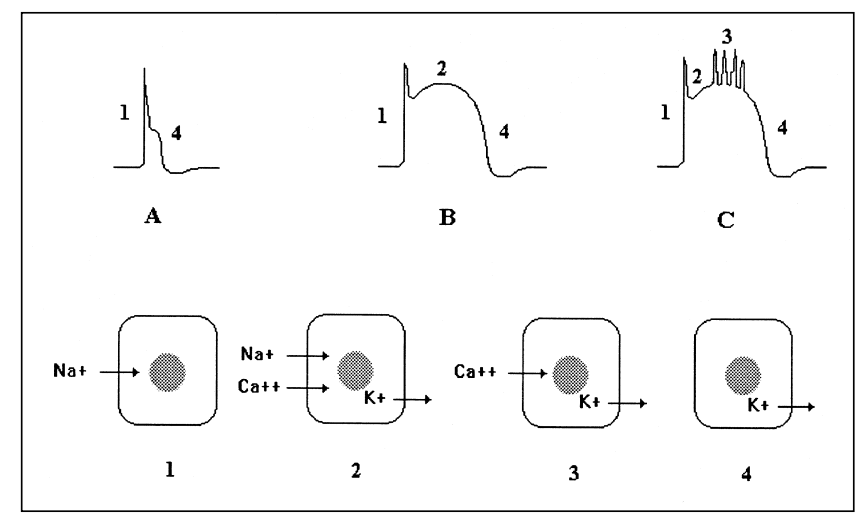

Figure 2) Ionic basis of gastric electrical activity. The presence of electrical control activity is associated with sodium-potassium unbalance (A). Dynamics of sodium, potassium and calcium ions are responsible for the plateau of electrical response activity (B), while an inflow of calcium ions through fast channels is predominantly related to spikes $(\mathbf{C})$. The amplitude of spikes is modified by an outward flow of potassium ions

along the greater curvature in the proximal corpus, and this area is often called a pacemaker $(6,7)$. ECA originates at this site and spreads instantaneously in a 2 to $2.5 \mathrm{~mm}$ ring around the circumference of the stomach $(9,15,19,20)$. This ring spreads distally at an increasing velocity to the pylorus. The ECA is omnipresent whether or not there are contractions. In humans it has a frequency of about 3 cycles/min.

The second component of GEA is electrical response activity, which can occur only superimposed on ECA and is associated with contractions $(6,9,17)$. It has two components: the plateau and spikes. The presence of spikes indicates a powerful contraction (15) (Figure 1).

These electrical events are due to ionic shifts across the smooth muscle cell wall. The ionic basis for membrane and action potential of the gastrointestinal smooth muscle cell and the basis for gastric motility have been described $(9,15,17,21)$. An inward sodium ion current is responsible for the initial depolarization of gastric smooth muscle cells, and both sodium ions and calcium ions (penetrating the cellular membrane through relatively slow channels) are involved in the generation of the plateau potential. The repolarization is attributable to an outward current caused by 
the movement of potassium ions. The spikes could be regarded as the result of two currents: an inward current related to the influx of calcium ions into the cell through fast transmembrane channels; and an outward potassium current that directly modifies the amplitude of the spikes diminishing it (Figure 2).

\section{RECORDING GEA}

Electrical activity of the stomach can be recorded in different ways; intracellular or extracellular recordings can be made from isolated muscle strips in vitro, and in vivo recordings can be made from the intact stomach with electrodes implanted through the mucosa or serosa, or by placing electrodes on the anterior abdominal wall. The appearance of the GEA waveform is greatly determined by the type of recording used during its acquisition (Figure 3). For example, by using short distance implanted bipolar recordings (needle electrodes separated $2.5 \mathrm{~mm}$ in a parallel direction to the gastric axis), ECA and spikes are clearly seen; however, the plateau is frequently not clearly evident. In contrast, long distance bipolar electrode recordings (needles implanted about $2 \mathrm{~cm}$ apart in a parallel direction to the gastric axis) clearly show the plateau, but the spikes can be easily missed (Figure 3).

Major changes in GEA wave form are observed when electrodes are placed at some distance from the gastric surface (eg, on the abdominal wall). The wave shape becomes smoother because of the filtering and integrating properties of the body. Other changes result from the superposition of GEA generated simultaneously from many sites on the stomach and recorded by the electrodes on the abdominal wall (22). As a result, the EGG wave shape is closer to a sine wave with a relatively narrow frequency spectrum. The spikes, with their high frequency, erratic appearance and minimal electrical power, are filtered and averaged so much that they cannot be recognized in EGG recordings $(22,23)$ (Figure 3).

Another distinct feature of GEA is the configuration of the electrical dipoles that form the gastric electrical field. In 1985, Mirrizzi et al (24) proposed a conical dipole model to describe the gastric electrical field. They pointed out that ECA is generated by the distal movement of an annular band polarized by electrical dipoles oriented perpendicularly to the stomach axis. This model was later improved by using a truncated conoid to represent the shape of the stomach and a spherical system of coordinates (25) (Figure 4). Computer modelling opens an exciting path towards a better understanding of the electrophysiological phenomena surrounding GEA and EGG.

\section{INTERDIGESTIVE AND DIGESTIVE PATTERNS OF GEA}

Many authors have described characteristic changes in the pattern of gastric contractions during the interdigestive period (26-30). The interdigestive migrating motor complex (IMMC) has been divided into four main phases: phase I or quiescent phase, in which spike activity is not present; phase II, in which there is clear evidence of spike activity in some

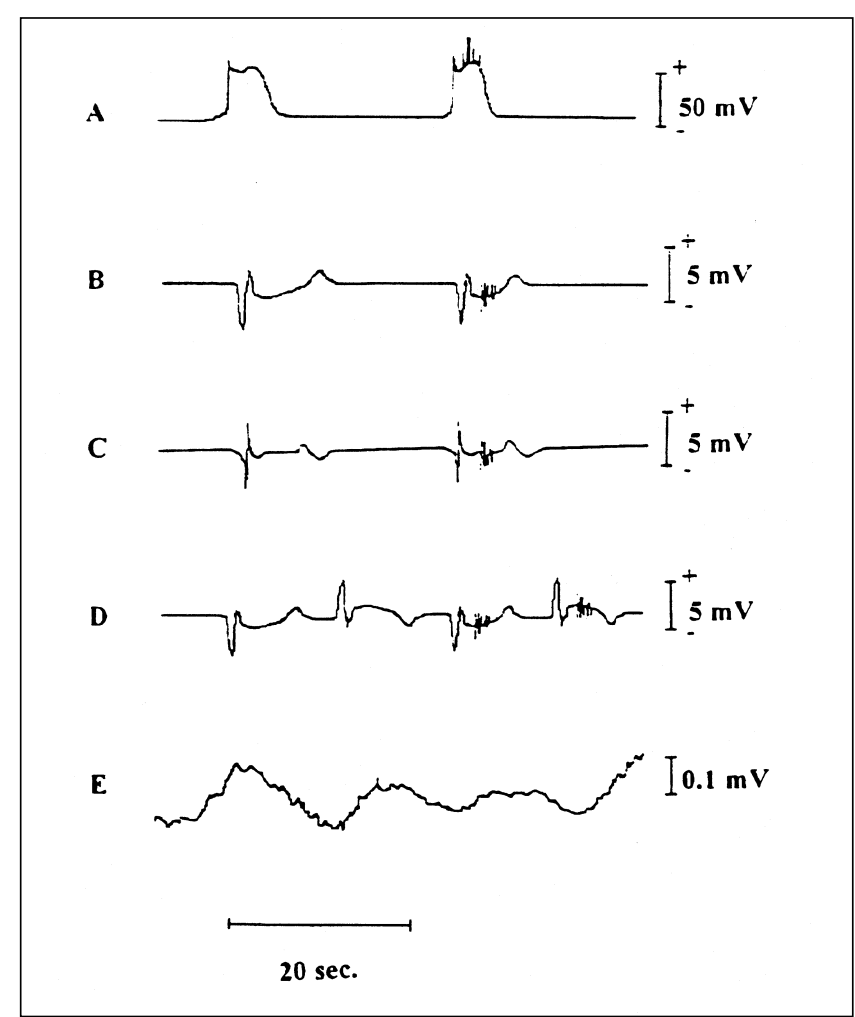

Figure 3) Recording gastric electrical activity. A Monopolar intracellular recording in vitro; B Monopolar extracelluar recording in vivo; C Short distance extracellular bipolar recording in vivo; D Long distance extracellular bipolar recording in vivo; E Electrogastrogram

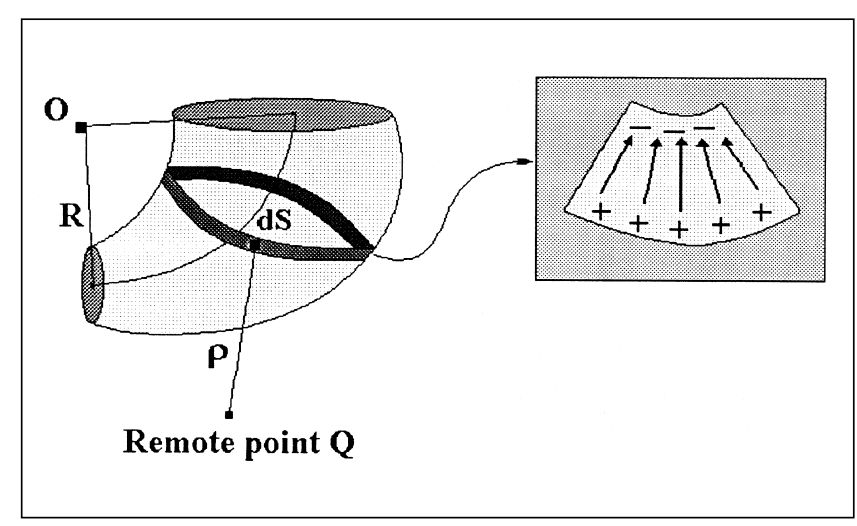

Figure 4) Conoidal dipole model of gastric electrical field in a spherical system of coordinates and detail of the dipoles pointing to the centre. O Centre; Q Electrode placed on abdominal wall at distance P from the stomach and $a$ band of depolarized cells (dS); R Radius-vector

ECA periods; phase III, in which every cycle of ECA is combined with spikes and therefore strong contractions occur with every slow wave; and phase IV, which is a brief transitional period similar to phase II. In humans the approximate duration of the interdigestive cycle is 2 to $2.5 \mathrm{~h}$, and the mean duration of phase III is only about 12 to 15 mins (26). After food ingestion, the IMMC pattern is interrupted and replaced by a distinctive digestive pattern $(26,29,30)$. The approximate duration of the digestive period after a standard 

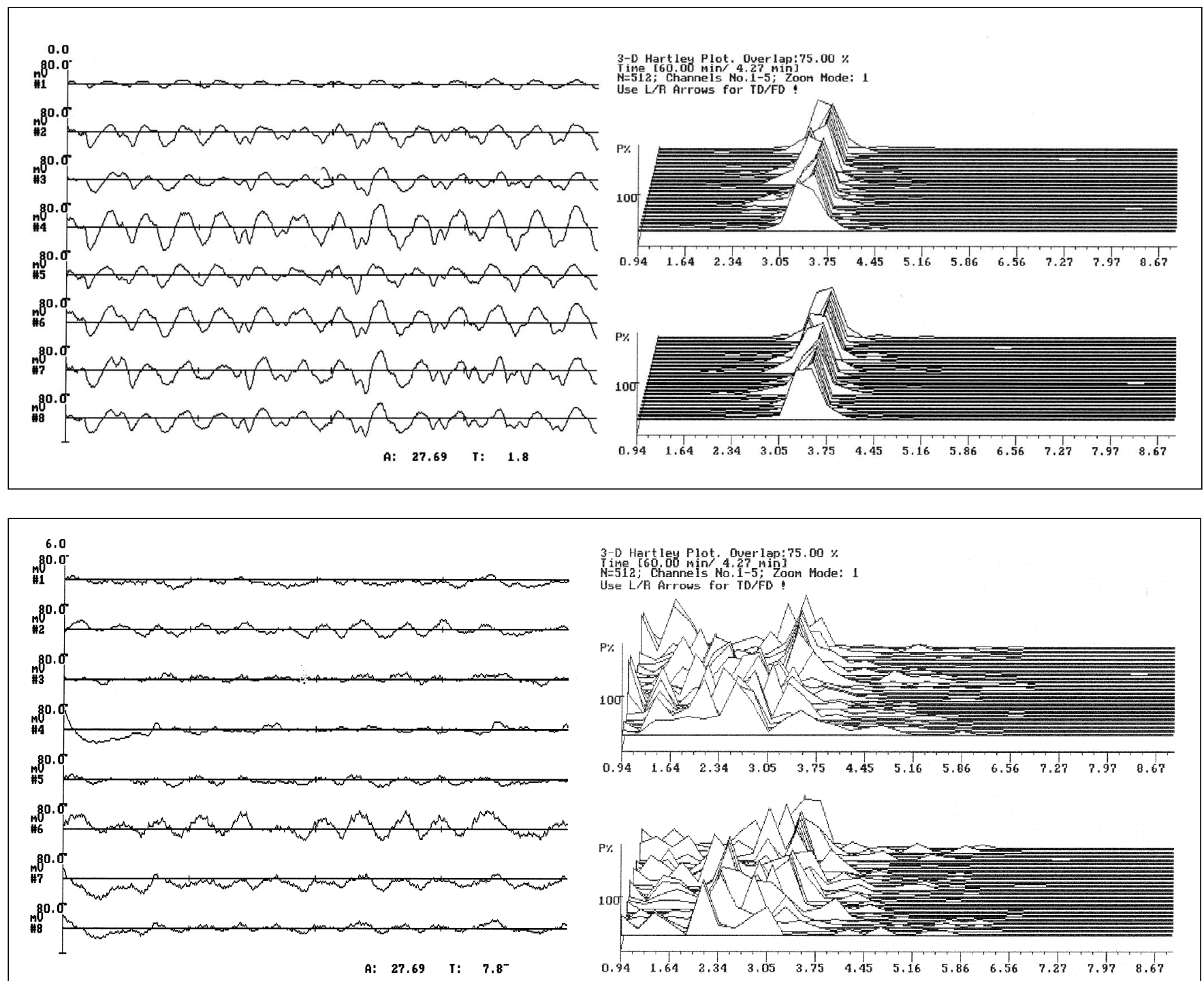

Figure 5) Electrogastrography (EGG) signals and their pseudo-three-dimensional plots. Top Normal gastric electrical activity. The pseudo-threedimensional plots show the power of the main gastric frequency in two EGG channels during the time of recording. Bottom Abnormal gastric electrical activity in a patient with gastric carcinoma and extensive infiltration of the gastric muscle layer. The plots show additional abnormal frequency components

meal ( $500 \mathrm{kcal})$ is 4 to $5 \mathrm{~h} \mathrm{(26).} \mathrm{During} \mathrm{this} \mathrm{period} \mathrm{there} \mathrm{are}$ regular contractions in the distal stomach related to spike bursts (26,27). Unfortunately, Geldof et al (28) found that EGG could not identify different phases of the IMMC.

\section{TECHNIQUES FOR EGG RECORDING AND EXTERNAL FACTORS THAT CAN INFLUENCE EGG VALIDITY}

There are several techniques for recording EGG, but in general bipolar recordings are more reliable than monopolar recordings (31). Mintchev and Bowes (32) introduced an eight-channel bipolar configuration for EGG acquisition that allows recording from multiple electrode combinations using short and long interelectrode distances, thereby enhancing the probability of obtaining a stable EGG recording.

Recording EGG is a technological challenge because the signal is usually contaminated with a large number of record- ing artefacts. These artefacts can be divided into three groups: random motion noise; periodic electrical or mechanical noise caused by other organs and respiration; and electrical noise due to the amplification process. In order to diminish the random motion noise, the subject should avoid any voluntary movement. To avoid noise caused by other organs and respiration, an adequate system of signal filtering and conditioning should be employed. These higher frequency artefacts combined with the essential anti-aliaising requirements for digitizing require low pass filters (33). After the initial filtering (usually in the range 0.03 to $0.3 \mathrm{~Hz}$ ) the signal is digitized so that more sophisticated and flexible digital filtering procedures can be implemented (34-37). The third type of electrical noise is related to the amplification process and is a complex issue, even from the perspective of contemporary electronics. The selection of adequate electrodes, their position on the abdominal wall, satisfactory 
skin preparation and the use of adequate low noise amplifiers are very important $(33,34)$. During the acquisition and amplification process, scrupulous skin preparation is necessary to reduce impedance of the electrode-skin interface and to ensure adequate electrode fixation to diminish noise due to displacement or bending of the electrodes (38). Also, the electrodes employed in EGG acquisition should produce as little noise as possible; fortunately most commercially available ECG electrodes fulfil this condition (38). It has been suggested that the electrode surface area has a significant impact on the EGG signal; smaller electrodes have been associated with a significant drop in the specificity of the EGG test (39).

\section{EGG ANALYSIS}

Digital analysis of EGG has been shown to reflect normal ECA frequency and its dynamics accurately (23,40-43). In order to quantify the changes in EGG frequency and its power over the recording time, most researchers employ a fast Fourier or fast Hartley transform and running spectrum analysis $(21,30,32-34)$. For this analysis raw EGG signals are generally conditioned using controlled bandpass preamplifiers (frequency bandpass about 0.03 to $0.08 \mathrm{~Hz}$ ). First the signals are digitized with a $10 \mathrm{~Hz}$ sampling frequency and filtered using a frequency sampling bandpass filter in the range of 0.02 to $0.1 \mathrm{~Hz}$. Then the EGG recordings are analyzed using $4 \mathrm{~min}$ time intervals to obtain a single frequency spectrum. Successive frequency spectra are arranged, overlapped and displayed as a pseudo-three-dimensional plot for each separate EGG channel. The advantages of overlapping signal intervals are improved interpretability of the spectra and the elimination of artefacts in the signal $(38,44,45)$. The pseudothree-dimensional plot shows the amplitude changes of the main gastric frequencies that occur over the time (Figure 5).

Another way to display this information is on grey scale plots in which small frequency variations and frequency patterns can be identified $(38,44,45)$. The pseudo-three-dimensional plots and grey scale plots provide a qualitative analysis of EGG frequency.

In order to develop a more quantitative approach to EGG analysis, mathematical and statistical analysis can be applied to EGG frequency and power variations. Analysis should include measurements of the EGG frequency stability over the time.

\section{VALIDATION OF EGG AND CLINICAL APPLICATIONS}

Enthusiasts of EGG report abnormalities in a large variety of clinical states including gastroparesis, dyspepsia, unexplained nausea and vomiting, anorexia nervosa, nausea and vomiting of pregnancy, and motion sickness (46-70). Careful perusal of the studies reporting these abnormalities does not always support their conclusions, and technical questions abound. Often the abnormalities are present in a minority of patients, there is usually no objective or quantitative analysis, and subsequent reports often fail to support the earlier claims.
The cart may, in fact, have been put in front of the horse. Ideally, before EGG can be clinically accepted as a valuable clinical adjunct, two fundamental questions must be answered: Are gastric motor abnormalities or disease states associated with abnormalities in GEA? Can EGG detect these abnormalities?

Although ECA is of prime importance in determining frequency and direction of propagation of contraction in the antrum, ECA itself does not provoke contractions. Conditions affecting gastric innervation would have a profound effect on gastric motor function without necessarily affecting ECA. Unfortunately, good recordings of GEA can be obtained only with electrodes implanted into the gastric serosa. Consequently, very few patients have been studied in this manner. Using subserosal implanted electrode recordings, Sarna et al (71) found abnormalities in frequency, coupling and regularity during postoperative ileus. Subsequent reports have confirmed these findings in patients after gastric and nongastric operations (72). Some studies have used transmucosal recordings obtained with a tube passed by mouth. Unfortunately, such recordings are full of artefacts due to variable contact to the mucosa and, in general, are not reliable. It is likely that EGG will have to prove itself without the important and ideal crutch of simultaneous recordings with implanted electrodes.

It has been suggested that EGG can recognize three parameters of GEA: frequency abnormalities (whether regular or irregular), uncoupling and gastric contractions.

There is strong evidence that EGG has a high accuracy in recognizing normal gastric electrical frequencies $(2,22,40$ $43,46)$. If a change in frequency persists for several minutes, it can also be recorded with EGG, but transient changes in frequency (which may not be relevant clinically) would be recognized with great difficulty $(73,74)$. Frequencies outside the normal range ( 2.5 to 3.75 cycles/min) have been reported in several diseases, and are termed bradygastria (fewer than 2.5 cycles/min) and tachygastria (more than 3.75 and less than 9 cycles/min) $(3,14,55,71,72)$. How a slightly slower or faster GEA frequency would affect gastric motor function is not clear. You and Chey (14) claimed that tachygastria could interfere with gastric contractions in studies on dogs. Mintchev et al (75) found that gastric electrical uncoupling can be seen at times as 'tachygastria' in EGG. However, the meaning and the reliability of EGG frequency abnormalities and the impact of external factors on the EGG frequency have not been adequately defined.

It has been claimed that electrodes on different parts of the abdomen can record GEA from different parts of the stomach. Although an electrode would be most affected by the area of stomach closest to it, cutaneous electrodes, in fact, pick up total GEA, and it is not possible to recognize uncoupling in this manner. There is some evidence that uncoupling might be revealed by the display after frequency analysis of two or more EGG main frequencies instead of the standard one. However, more studies using the gold standard (recordings obtained from electrodes implanted in gastric serosa) and EGG simultaneously should be done to confirm 
these claims. The uncertain role of EGG in detecting uncoupling is particularly unfortunate because slight changes in frequency may not be very important in gastric motor function, but uncoupling of different parts of the stomach from each other would have a profound effect on gastric emptying.

It has been suggested that changes in amplitude of EGG are related to gastric contractions $(2,41,42,53)$. Certainly EGG amplitude often increases after the subject eats, and much better quality records are usually obtained. However, gastric distention and displacement play an important role in these changes in amplitude, and changes in EGG amplitude do not correlate with gastric mechanical activity (40, 54). Several studies have found a postprandial increase in EGG amplitude in only some normal volunteers and experimental models $(40,76,77)$.

Ideally, studies of EGG should incorporate the use of multiple cutaneous electrodes and, if possible, computer analysis. If visual analysis alone is used, it should be done blindly by two different observers, and quantification should be attempted. Computer analysis is ideal for objective quantitative analysis and allows interpretation of many records that are clouded with artefacts.

Unfortunately, few studies have examined the ability of EGG to recognize GEA abnormalities $(14,40,46,73,74,78)$. This lack of information along with the other considerations mentioned above seriously question the clinical utility of EGG.

Multiple studies have tried to identify a relationship between EGG and gastric emptying (46-52). Some initial reports claimed that EGG frequency abnormalities were found in patients with gastroparesis (47-49), but these abnormalities were seen in only a few patients. In one of the studies the resolution of EGG dysrhythmias after treatment with a prokinetic drug did not correlate with improvement of gastric emptying rates. Another study did not find significant differences in the incidence of EGG dysrhythmias in gastroparetic patients and in healthy controls (50).

Several studies have failed to detect a good correlation between EGG findings and gastric emptying rates (46,5052). One of the better studies analyzed both internal GEA and EGG in patients with proven gastroparesis and found no alterations in slow wave frequency recorded by implanted electrodes or EGG (46). The only abnormality in these patients was a diminished spike activity in the internal recordings that was not reflected in EGG recordings.

Contradictory findings have also been shown when relating abnormal EGG to other diseases. For example, it was suggested that EGG abnormalities were frequent in patients with anorexia nervosa (55). However, EGG data were analyzed visually, the episodes of dysrhythmias were transient (usually less than 3 mins) and their total duration was less than $12 \%$ of the total recording time. The percentage of dysrhythmias increased after treatment without modification of gastric emptying or antral motility. Finally, a subsequent study revealed normal EGG frequency dynamics in patients with anorexia nervosa (56).
The quest for an explanation for dyspeptic symptoms has led several authors to try to find a relationship between abnormal GEA and this syndrome. An increased frequency of tachygastria has been described in dyspeptic patients (57). This finding was, however, only significant in fasting EGG recordings when the EGG signals tend to be weaker and, consequently, more predisposed to be contaminated by noise. Postprandially, when dyspeptic symptoms usually appear and better EGG signals are generally obtained, the EGG was normal.

Stern and co-workers (59) described tachygastria in healthy volunteers in whom motion sickness was induced. Unfortunately, there was not a clear relationship between the onset of the symptoms and the onset of the tachygastria; in six of the 10 symptomatic subjects the symptoms were exhibited before the tachygastric episode, and in three of the 10 , symptoms and EGG alterations appeared simultaneously, leaving only one in whom tachygastria was present before the onset of symptoms. Other studies have related nausea and vomiting to EGG frequency abnormalities $(60,61)$. Unfortunately, the EGG abnormalities were not confirmed with implanted gastric electrode recordings in any of these studies.

In summary, interpretation of most of these studies has been hindered by the lack of validation of the relationship between abnormal GEA and abnormal EGG. Ideally, further studies would encompass comparative studies in humans showing the following: that any abnormal frequency recorded in EGG correlates reliably with internal GEA frequency abnormalities and vice versa; the impact of external factors on EGG recordings; and the clinical significance of transient abnormalities in GEA frequency.

\section{CONCLUSIONS}

EGG has been shown to be a more or less accurate reflection of ECA frequency when proper recording technique is scrupulously observed. Although numerous studies have tried to elucidate relationships between EGG abnormalities and many gastrointestinal and nongastrointestinal clinical disorders, it is not yet possible to confirm any significant correlation between EGG abnormalities and any specific disease. When performed with the available technology, EGG is still not validated as a reliable diagnostic test for gastric motility disorders. Because better techniques for digital processing and analysis are being developed, this technique may soon provide some supplementary information to the routinely available tests for assessing gastric motility and emptying.

\section{REFERENCES}

1. Alvarez WC. The electrogastrogram and what it shows. JAMA 1922;78:1116-8.

2. Smout AJPM, Van der Schee EJ, Grashuis JL. What is measured in electrogastrography? Dig Dis Sci 1980;25:179-86.

3. You CH, Lee KY, Chey WY, Menguy R. Electrogastrographic study of patients with unexplained nausea, bloating, and vomiting. Gastroenterology 1980;79:311-4.

4. Chen J, McCallum RW. Electrogastrography: measurement, analysis and prospective applications. Med Biol Eng Comput 1991;29:339-50.

5. Cannon WB. The movements of the stomach studied by means of the Roentgen rays. Am J Physiol 1898;1:359-82. 
6. Kelly KA. Gastric emptying of liquids and solids: roles of proximal and distal stomach. Am J Physiol 1980;239:G71-6.

7. Cooke AR. Control of gastric emptying and motility. Gastroenterology 1975;68:804-16.

8. Stemper TJ, Cooke AR. Gastric emptying and its relationship to antral contractile activity. Gastroenterology 1975;69:649-53.

9. Szurszewski J. Electrical basis for gastrointestinal motility. In: Johnson LR, ed. Physiology of the Gastrointestinal Tract. New York: Raven Press, 1981:1435-66.

10. Dent J, Sun WM, Anvari M. Modulation of pumping function of gastric body and antropyloric contractions. Dig Dis Sci 1994;39(12 Suppl):28S-31S.

11. Horrowitz M, Dent J, Fraser T, Sun W, Hebbard G. Role and integration of mechanisms controlling gastric emptying. Dig Dis Sci 1994;39(12 Suppl):7S-13S.

12. Azpiroz F. Control of gastric emptying by gastric tone. Dig Dis Sci 1994;39(12 Suppl):18S-9S.

13. Camillieri M, Prather CM. Axial forces during gastric emptying in health and models of disease. Dig Dis Sci 1994;39(12 Suppl): 14S-7S.

14. You CH, Chey WY. Study of electromechanical activity of the stomach in humans and in dogs with particular attention to tachygastria. Gastroenterology 1984;86:1460-8.

15. Papasova M. An electrophysiological study on the motor activity of the stomach. In: Chey WY, ed. Functional Disorders of the Digestive Tract. New York: Raven Press, 1983:135-42.

16. Bortoff A. Myogenic origin of gut motility. In: Chey WY, ed. Functional Disorders of the Digestive Tract. New York: Raven Press, 1983:93-101.

17. Morgan KG, Muir TC, Szurszewski JH. The electrical basis for contraction and relaxation in canine fundal smooth muscle. J Physiol 1981;311:475-88.

18. Sarna SK. Gastrointestinal electrical activity: terminology. Gastroenterology 1975;68:1631-5.

19. Weber J, Kohatsu S. Pacemaker localization and electrical conduction patterns in the canine stomach. Gastroenterology 1970;59:717-26.

20. Kelly KA, Code CF. Canine gastric pacemaker. Am J Physiol 1971;220:112-8.

21. El-Sharkawy TY, Morgan KG, Szurszewski JH. Intracellular electrical activity of canine and human gastric smooth muscle. J Physiol 1978;279:291-307.

22. Familoni BJ. Validity of the cutaneous electrogastrogram. In: Chen JJ, McCallum RW, eds. Electrogastrophy: Principles and Applications. New York: Raven Press, 1994:103-25.

23. Familoni BO, Kingma YJ, Bowes KL. Study of transcutaneous and intraluminal measurement of gastric electrical activity in humans. Med Biol Eng Comput 1987;25:397-402.

24. Mirrizzi N, Stella R, Scafoglieri U. A model of extracellullar waveshape of the gastric electrical activity. Med Biol Eng Comput 1985;23:33-7.

25. Mintchev MP, Bowes KL. Conoidal dipole model of electrical field produce by the human stomach. Med Biol Eng Comput 1995;3:179-84.

26. Itoh Z, Sekiguchi T. Interdigestive motor activity in health and disease. Scand J Gastroenterol Suppl 1982;82:121-34.

27. Gill RC, Pilot MA, Thomas PA, Wingate DL. Organization of fasting and postprandial myoelectric activity in stomach and duodenum of conscious dogs. Am J Physiol 1985;249:G655-1.

28. Geldof H, Van der Schee EJ, Grashuis JL. Electrogastrographic characteristics of interdigestive migrating complex in humans. Am J Physiol 1986;250:G165-71.

29. Code CF, Marlett JA. The interdigestive myo-electric complex of the stomach and small bowel of dogs. J Physiol 1975;246:289-309.

30. Smout AJPM, Van der Schee EJ, Akkermans LMA, Grashuis JL. Recording of gastrointestinal electrical activity from surface electrodes. Scand J Gastroenterol 1984;19(Suppl 96):11-8.

31. Hamilton JW, Bellahsene BE, Cascio DS, Webster RN, Bass P. Human electrogastrograms: Comparison of techniques of recording. Am J Gastroenterol 1988;83:806-11.

32. Mintchev MP, Bowes KL. Impact of external factors on the stability of human electrogastrograms. Med Biol Eng Comput 1996;34:270-2.

33. Webster JG. Amplifiers and signal processing. In: Webster JG, ed. Medical Instrumentation. Application and Design, 2nd edn. Boston: Houghton Mifflin Company, 1992:112-49.

34. Mintchev MP, Bowes KL. A new look at the amplification of gastric electrical signals. In: 17th International Conference of the Engineering in Medicine and Biology Society of the Institute of Electronics Engineers (IEEE-EMBS). Montreal, Quebec, September 18-25, 1995.

35. Ketie MA, Van der Schee EJ, Grashuis JL, Smout AJPM. Adaptive filtering of canine electrogastrographic signals. Part 1: system design. Med Biol Eng Comput 1981;19:759-64.

36. Ketie MA, Van der Schee EJ, Grashuis JL, Smout AJPM. Adaptive filtering of canine electrogastrographic signals. Part 2: filter performance. Med Biol Eng Comput 1981;19:765-9.

37. Chen J. Adaptive Filtering and Its Application in Echo Cancellation and Biomedical Signal Processing. PhD Thesis. Katholieke Universiteit Leuven, 1989.

38. Smout ALPM, Jebbink HJA, Samson M. Acquisition and analysis of electrogastrographic data. The Dutch experience. In: Chen JJ, McCallum RW, eds. Electrogastrography: Principles and Applications. New York: Raven Press, 1994:3-30.

39. Mintchev M, Stickel A, Bowes K. Impact of different electrode surface areas in validity of human electrogastrograms. Med Biol Eng Comput 1997;35:66-8.

40. Mintchev MP, Knigma YJ, Bowes KL. Accuracy of cutaneous recordings of gastric electrical activity. Gastroenterology 1993;104:1273-80.

41. Bellahsene BE, Hamilton JW, Webster JG, Bass P, Reichelderfer M. An improved method for recording and analyzing the electrical activity of the human stomach. IEEE Trans Biomed Eng 1985;32:911-5.

42. Chen J, McCallum RW. Response of the electric activity in the human stomach to water and solid meal. Med Biol Eng Comput 1991;29:351-7.

43. Mintchev MP, Bowes KL. Extracting quantitative information from digital electrogastrograms. Med Biol Eng Comput 1996;34:244-8.

44. Koch KL, Stern RM. Electrogastrographic data. Acquisition and analysis. The Penn State experience. In: Chen JJ, McCallum RW, eds. Electrogastrography: Principles and Applications. New York: Raven Press, 1994:31-44.

45. Van der Schee EJ, Smout AJPM, Grashuis JL. Application of running spectrum analysis to electrogastrographic signals recorded from dog and man. In: Wienbeck M, ed. Motility of the Digestive Tract. New York: Raven Press, 1982:241-50.

46. Chen J, Schirmer BD, McCallum RW. Serosal and cutaneous recordings of gastric myoelectrical activity in patients with gastroparesis. Am J Physiol 1994;266:G90-8.

47. Chen J, McCallum RW. Gastric slow wave abnormalities in patients with gastroparesis. Am J Gastroenterol 1992;87:477-82.

48. Chen J, Lin Z, Pan P, McCallum R. Abnormal gastric myoelectrical activity and delayed gastric emptying in patients with symptoms suggestive of gastroparesis. Dig Dis Sci 1996;41:1538-45.

49. Koch KL, Stern RM, Stewart WR, Vasey MW. Gastric emptying and gastric myoelectrical activity in patients with diabetic gastroparesis: Effect of long term domperidone treatment. Am J Gastroenterol 1989;84:1069-75.

50. Jebbink HJA, Bruijs PPM, Bravenboer B, Akkermans LMA, vanBerge-Henegouven GP, Smout AJPM. Gastric myoelectrical activity in patients with type I diabetes mellitus and autonomic neuropathy. Dig Dis Sci 1994;39:2376-83.

51. Pfaffenbach B, Wegener M, Adamek RJ, Schaffstein J, Lee YH, Ricken D. Antral myoelectric activity, gastric emptying and dyspeptic symptoms in diabetics. Scand J Gastroenterol 1995;30:1166-71.

52. Pfaffenbach B, Adamek RJ, Hagemann D, et al. Effect of progressive systemic sclerosis on antral myoelectrical activity and gastric emptying. Z Gastroenterol 1996;34:517. (Abst)

53. Chen J, Richards RD, McCallum R. Identification of gastric contractions from the cutaneous electrogastrogram. Am J Gastroenterol 1994;89:79-85.

54. Pfaffenbach B, Wedmann B, Adamek RJ, Wegener M. The significance of electrogastrographically determined amplitudes is there a correlation to sonographically measured antral mechanical contractions? Z Gastroenterol 1995;33:103. (Abst)

55. Abell TL, Malagelada JR, Lucas AR, et al. Gastric electromechanical and neurohormonal function in anorexia nervosa. Gastroenterology 1987;93:958-64

56. Ravelli AM, Helps BA, Devane SP, Lask BD, Milla PJ. Normal gastric antral myoelectrical activity in early onset anorexia nervosa. Arch Dis Child 1993;69:342-6.

57. Pfaffenbach B, Adamek RJ, Bartholomaus C, Wegener M. Gastric 
dysrhythmias and delayed gastric emptying in patients with functional dyspepsia. Dig Dis Sci 1997;42:2094-9.

58. Riezzo G, Cucchiara S, Chiloro M, Minella R, Guerra V, Giorgio I. Gastric emptying and myoelectrical activity in children with non-ulcer dyspepsia. Effect of cisapride. Dig Dis Sci 1995;40:1428-34.

59. Stern RM, Koch KL, Steward WR. Spectral analysis of tachygastria recorded during motion sickness. Gastroenterology 1987;92:92-7.

60. Geldof H, Van der Schee EJ, Van Blankenstein M, Grashuis JL. Electrogastrographic study of gastric myoelectrical activity in patients with unexplained nausea and vomiting. Gut 1986;27:799-808.

61. Koch KL, Stern RM, Vasey M, Botti JJ, Creasy GW, Dwyer A. Gastric dysrhythmias and nausea of pregnancy. Dig Dis Sci 1990;35:961-8.

62. Tomomasa T, Miyazaki M, Nako Y, Kuroume T. Electrogastrography in neonates. J Perinatol 1994;14:417-21.

63. Cucchiara S, Minella R, Riezzo G, et al. Reversal of gastric electrical dysrhythmias by cisapride in children with functional dyspepsia. Report of three cases. Dig Dis Sci 1992;37:1136-40.

64. Cucchiara S, Riezzo G, Minella R. Electrogastrography in non ulcer dyspepsia. Arch Dis Child 1992;67:613-7.

65. Devane SP, Milla PJ. Gastric antral dysrhythmias in childhood intestinal pseudo-obstruction. In: Chen JJ, McCallum RW, eds. Electrogastrography: Principles and Applications. New York: Raven Press, 1994:397-402.

66. Ravelli AM, Milla P. Electrogastrography in vomiting children with disorders of the central nervous system. In: Chen JJ, McCallum RW, eds. Electrogastrography: Principles and Applications. New York: Raven Press, 1994:403-10.

67. Koch KL, Tran TR, Stern MR, Bigaman S, Sperry N. Gastric myoelectric activity in premature and term infants. J Gastrointest Motil 1993;5:41-8.

68. Riezzo G, Pezzolla F, Darconza G, Giorgio I. Gastric myoelectrical activity in the first trimester of pregnancy: A cutaneous electrogastrographic study. Am J Gastroenterol 1992;87:702-7.

69. Geldof H, Van der Schee EJ, Smout AJPM, van de Merwe JP, van Blankenstein M, Grashuis JL. Myoelectrical activity of the stomach in gastric ulcer patients: an electrogastrographic study. J Gastrointest Motil 1989;1:122-30.

70. Debinski HS, Ahmed S, Milla PJ, Kanm MA. Electrogastrography in chronic intestinal pseudoobstruction. Dig Dis Sci 1996;41:1292-7.

71. Sarna SK, Bowes KL, Daniel EE. Post-operative gastric electrical control activity (ECA) in man. In: Daniel EE, ed. Proceedings of the Fourth International Symposium on Gastrointestinal Motility, Banff, Alberta, 1973. Vancouver: Mitchell Press, 1974:73-83.

72. Stoddard CJ, Smallwood RH, Duthie HL. Electrical arrhythmias in the human stomach. Gut 1981;22:705-12.

73. Abell TL, Malagelada JR. Glucagon-evoked gastric dysrhythmias in humans shown by an improved electrogastrographic technique. Gastroenterology 1985;88:1932-40.

74. Familoni BO, Bowes Kl, Kingma YJ, Core KR. Can transcutaneous recordings detect gastric electrical abnormalities? Gut 1990;32:141-6.

75. Mintchev MP, Otto SJ, Bowes KL. Electrogastrography can recognize gastric electrical uncoupling in dogs. Gastroenterology 1997;112:2006-11.

76. Pfaffenbach B, Adamek RJ, Kuhn K, Wegener M. Electrogastrography in healthy subjects. Evaluation of normal values, influence of age and gender. Dig Dis Sci 1995;40:1445-50.

77. Mintchev MP, Stickel A, Bowes KL. Comparative assessment of power dynamics of gastric electrical activity. Dig Dis Sci 1997;42:1154-7.

78. Sun WM, Smout A, Malbert C, et al. Relationship between surface electrogastrography and antropyloric pressures. Am J Physiol 1995;31:G424-30. 


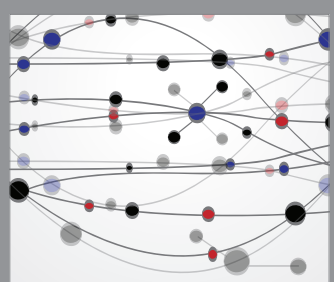

The Scientific World Journal
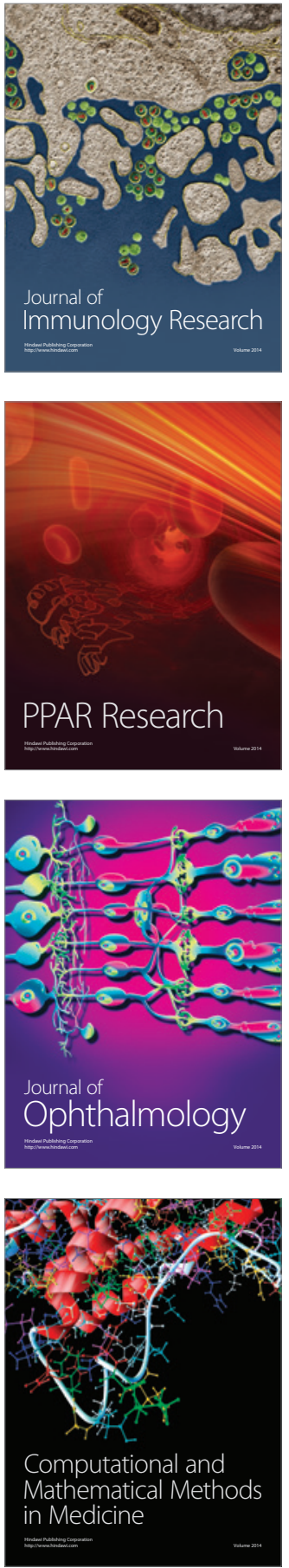

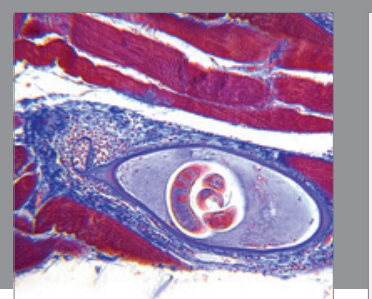

Gastroenterology Research and Practice

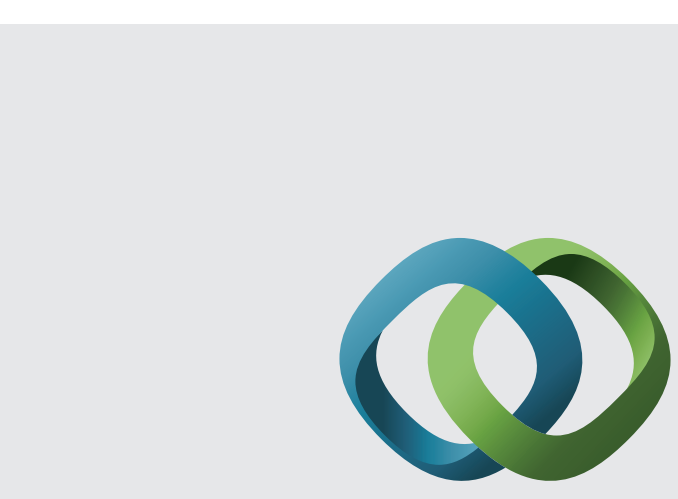

\section{Hindawi}

Submit your manuscripts at

http://www.hindawi.com
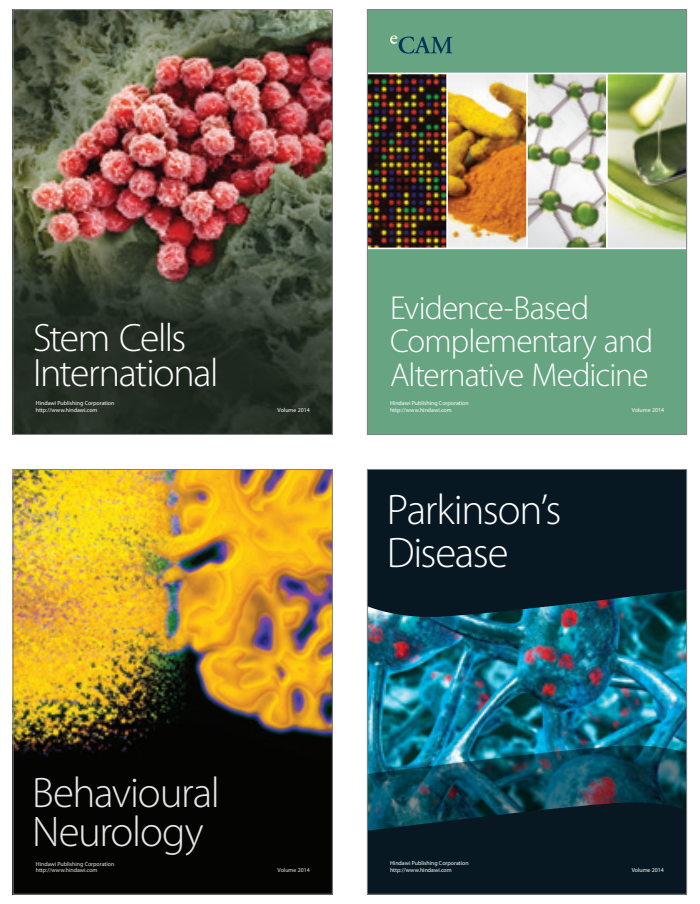
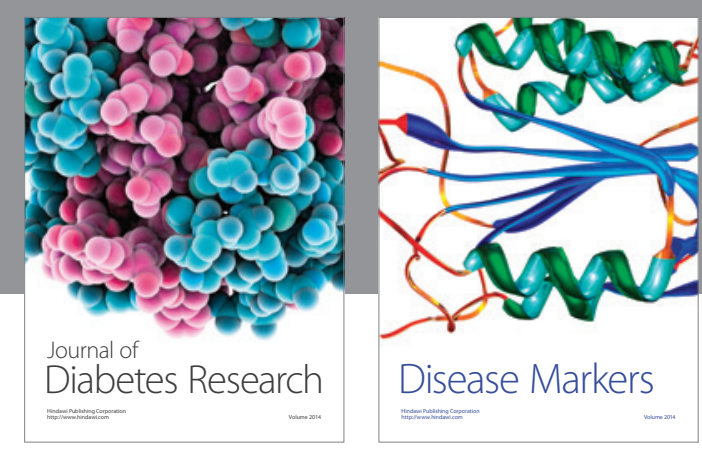

Disease Markers
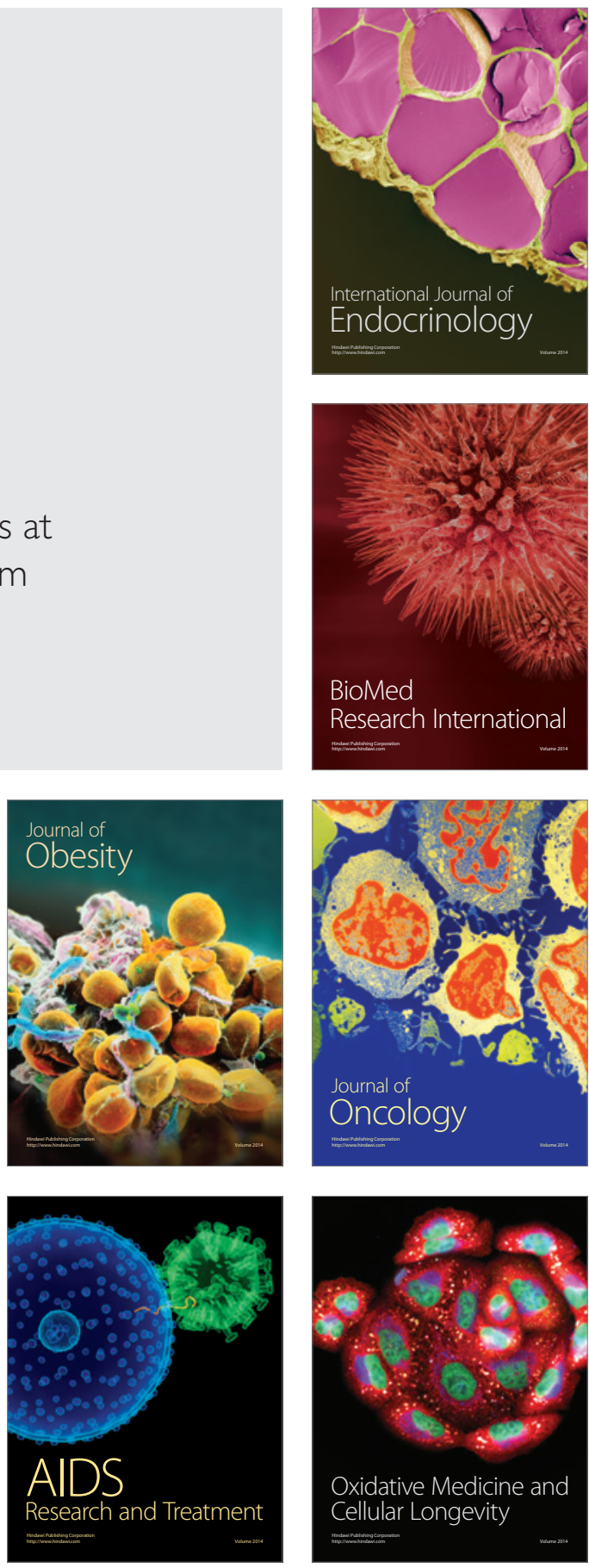